\title{
Impactos socioambientais e insegurança hídrica: o caso do Complexo Logístico, Industrial e Portuário do Açu (CLIPA), no estado do Rio de Janeiro
}

Rosangela Maria Amorim Benevides Guimaraes

DOI - 10.25160/v5i2.d9

\section{Contextualizando a questão da água no Brasil}

No Brasil dos anos 2000, a mídia brasileira veiculou situações de insegurança hídrica em estados e localidades do país, como o problema de abastecimento hídrico em 2014, no estado de São Paulo, que teve como hipóteses para as causas, a estiagem e gestão deficitária dos recursos hídricos, e o comprometimento de abastecimento de água para a população, além dos problemas na agricultura e pecuária, ocorridos em 2016, em municípios do estado do Espirito Santo, consequência da seca e estiagem. (MERCURI, 2014; GORRITII, 2016)

Em 2015, o rompimento da barragem de Fundão, no município de Mariana/MG, que armazenava rejeitos de minério de ferro da empresa Samarco, contaminou o rio Doce, afetando o abastecimento de água em municípios dos estados de Minas Gerais e Espírito Santo, além de comprometer atividades de subsistência, como a pesca e a agricultura. (IBAMA, 2015)

Tem aumentado os conflitos e a disputa em torno do acesso a água, motivados pela baixa oferta e pela qualidade duvidosa, em função de eventos extremos como a seca e a estiagem, inundações, apropriação privada da água, gestão deficitária da água, ausência de saneamento básico, degradação ambiental, desastres socioambientais relacionados a atividades econômicas de risco e impactos sobre os recursos hídricos devido à construção e operacionalização de grandes obras.

As construções da hidrelétrica de Jirau, no Rio Madeira, Porto Velho/RO, a Usina de Belo Monte, no rio Xingu, Pará, o Complexo Petroquímico do Rio de Janeiro (COMPERJ), em Itaboraí/RJ, exemplificam o que tem ocorrido no país. Populações tradicionais, pequenos agricultores, pescadores artesanais, veem alterados seus modos de vida e de subsistência, com desapropriação de terras, apropriação dos recursos naturais, contaminação e poluição das águas.

Tendo em vista que os direitos humanos são recorrentemente violados no país, fruto da desigualdade socioeconômica, da omissão do Estado na prestação de serviços 
sociais básicos, da má gestão pública, bem como de interesses econômicos e políticos excludentes, que tem na mundialização da economia e no consequente acirramento da competitividade entre empresas e grupos transnacionais, seu mote, Dornelles (2007, p. 210-211) traz uma reflexão:

\begin{abstract}
"Quando o mercado vai demasiado longe, dominando os resultados sociais e políticos, as oportunidades e recompensas da globalização difundem-se de forma desigual e não equitativa, quando as motivações do lucro dos atores do mercado ficam fora de controle, desafiam a ética das pessoas e sacrificam o respeito pela justiça e direitos humanos."
\end{abstract}

Dentro desse contexto, a região norte do estado do Rio de Janeiro, com sua formação sociohistórica e econômica calcadas na monocultura da cana-de-açúcar, no trabalho escravo, em traços culturais autoritários, constituída de uma elite econômica e política parasitária e exploradora, alto nível de desigualdade socioeconômica (CRUZ, 2004), nos anos 2000, recebe investimentos via grandes empreendimentos como o Complexo Logístico, Industrial e Portuário do Açu (CLIPA), que interfere negativamente nas condições de subsistência de comunidades, que já vivenciam a vulnerabilidade e exclusão cotidianas, e que atualmente, são afetadas por impactos socioambientais, como a salinação das águas.

A implantação do CLIPA vem apresentando recorrentes violações aos direitos, identificadas quando da ocorrência de desapropriações, efeitos danosos sobre o meio ambiente, afetando formas tradicionais de sobrevivência, como de pescadores e pequenos agricultores, onde a água tem centralidade, visto que mudanças que impactam negativamente no seu acesso provocam insegurança hídrica.

\title{
Caminhos para a construção da água como um direito humano
}

Em escala internacional, a água é elemento de disputa entre os grandes e poderosos conglomerados de empresas da água, que a veem como um bem privado, de valor econômico. Outros, como movimentos sociais, ONGs e outras instituições em nível internacional e nacional, lutam pela concretização da água como Direito Humano Fundamental.

Pode-se dizer que a construção do direito humano a água, inicia-se com a primeira Conferência da Organização das Nações Unidas (ONU) que ocorreu na Suécia, em 1972, 
sobre Meio Ambiente Humano, onde, pela primeira vez, a comunidade internacional se reúne para tratar de questões ambientais, diante dos desequilíbrios ambientais, próprios de um desenvolvimento desigual, e a necessidade de preservação e uso dos recursos naturais. Porém, é em 1977, que acontece a primeira Conferência especificamente sobre o tema água, em Mar Del Plata, na Argentina. Esta conferência demostrou a preocupação internacional com o aumento de demanda pela água, a degradação ambiental, o desenvolvimento desigual e seus efeitos nos recursos hídricos. (VARGAS, 2000)

Em Dublin, Irlanda, em 1992, acontece a Conferência Internacional sobre Água e Meio Ambiente, que contribui para a implementação de pactos sobre a gestão dos recursos hídricos, haja vista a sua deterioração, finitude e vulnerabilidade. O relatório desta conferência apresenta pontos relevantes para a questão hídrica, como a relação entre água e doença, o estímulo à aplicação de técnicas de reaproveitamento de água, o desenvolvimento humano, a produção agrícola, os conflitos geopolíticos em torno de bacias hidrográficas, o abastecimento de água potável nas áreas rurais, a proteção e conservação da água. Desta Conferência foi elaborada a Declaração Universal dos Direitos da Água, que em seu artigo 2º afirma ser a água um direito fundamental do ser humano, e também, com base nesta Conferência, a ONU se posicionou diante da exclusão hídrica, aprovando em sua 29a sessão, realizada em Genebra, em 2002, a Observação Geral n. 15 a qual se refere aos artigos 11 e 12, que tem como título "direito à água". (FERREIRA, 2011)

No entanto, para Gomes (2010), a Declaração de Dublin passou a ser o principal documento de referência da água como um bem de valor privado, ao defender a mercantilização da água, protegendo interesses de organismos internacionais como Banco Mundial, FMI e as grandes corporações do mercado da água. Assim se refere o documento da Conferência de Dublin sobre a água em uma perspectiva de desenvolvimento (ONU, 1992 apud GOMES, 2010, p. 6487).

“A água tem um valor econômico em todos os seus vários usos e deveria ser reconhecida como um bem econômico. Seguindo este princípio, é especialmente crucial reconhecer o direito básico de todos os seres humanos a terem acesso à água potável e ao saneamento a um preço que possam pagar. A inabilidade em reconhecer o valor econômico da água no passado levou ao desperdício e a usos que foram prejudiciais ao meio ambiente. Gerenciar a água como um bem econômico é um passo importante para a obtenção de um uso eficiente e igualitário, e para o encorajamento da conservação e proteção dos recursos hídricos." 
No Brasil, em 1992, aconteceu na cidade do Rio de Janeiro, a segunda Conferência das Naç̃es Unidas sobre Meio Ambiente e Desenvolvimento. Neste fórum foi produzida a Agenda 21, considerada importante documento, ao tratar da integração entre sociedade e natureza, incorporando preocupações ambientais, sociais, econômicas e culturais. (VARGAS, 2000; CUNHA et al, 2010)

Na Agenda 21, no capitulo 18, que trata da Proteção da qualidade do abastecimento dos recursos hídricos: aplicação de critérios integrados no desenvolvimento, manejo e uso dos recursos hídricos, dispõe:

“A água é necessária em todos os aspectos da vida. O objetivo geral é assegurar que se mantenha uma oferta adequada de água de boa qualidade para toda a população do planeta, ao mesmo tempo em que se preserve as funções hidrológicas, biológicas e químicas dos ecossistemas, adaptando as atividades humanas aos limites da capacidade da natureza e combatendo vetores de moléstias relacionadas com a água. Tecnologias inovadoras, inclusive o aperfeiçoamento de tecnologias nativas, são necessárias para aproveitar plenamente os recursos hídricos limitados e protegê-los da poluição."

Além dos eventos da ONU sobre a água, foi criado em 1995, o Conselho Mundial das Águas (World Water Counc - WWC), uma organização internacional que tem como objetivo refletir sobre os recursos de água doce. O WWC realiza de três em três anos, fóruns visando à participação e o diálogo entre governos, sociedade civil, empresas e especialistas. Desde 1997 já foram realizados sete edições do Fórum Mundial das Águas.

O 1 o Fórum Mundial da Água aconteceu em 1997, em Marrocos, discutiu o papel da água para o desenvolvimento sustentável. Em 2000, o 2o Fórum, realizado em Haia, discutiu a gestão de recursos hídricos. O 3º Fórum aconteceu em 2003, no Japão e deu prioridade aos compromissos assumidos nos fóruns anteriores. Segundo Ferreira (2011), neste foi reafirmado a água como um bem econômico e social, devendo prioritariamente atender às necessidades básicas humanas. Em 2006, aconteceu o $4^{\circ}$ Fórum, na Cidade do México, com o tema: Água para o Desenvolvimento, a Gestão Integrada, Saneamento, Alimentação, Meio Ambiente e a Gestão de Riscos. O 5ํㅜ Fórum, ocorrido em Istambul, em 2009, contemplou temas como mudança global, gestão de riscos, educação, conhecimento e desenvolvimento de capacidades. O 60 Fórum em Marselha, em 2012, abordou temas como governança global, segurança alimentar, adaptação às mudanças climáticas e crescimento verde. (6- WORD WATER FORUM, 2012; CUNHA et al, 2010) 


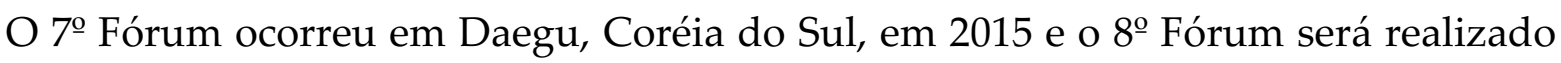
em Brasília, Brasil, em 2018. Tratando sobre o 5o Fórum, Barban (2009, p. 3) refere-se às principais controvérsias ocorridas nesses eventos:

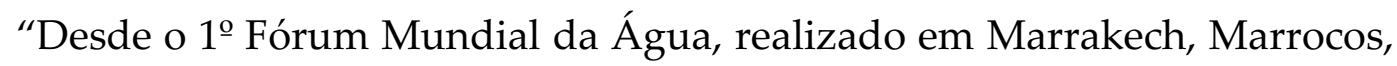
em 1997, as principais controvérsias centram-se entre a favor ou contra tratar a água como um bem comercializável. Este tem sido um dos pontos mais acalorados nesses fóruns: a questão da água como um direito humano e as recusas de tratá-la como uma mercadoria, em que a privatização dos serviços da água é a sua face mais visível e nem sempre a mais preocupante."

Além desses espaços de discussão sobre a água, citados acima, existem outros fóruns organizados pela sociedade civil, como o Fórum Global que ocorreu na cidade do Rio de Janeiro, no mesmo período do ECO 92. Segundo Ribeiro (2008, p. 64 apud CUNHA et al, 2010)

"Para as ONGs, a falta de água exige um outro modelo de sociedade, cujo processo de desenvolvimento deve envolver a participação popular nos diversos níveis de gestão [...] As ONG's foram mais longe que os que defendem o direito à água aos seres humanos, incorporando todas as manifestações da vida na luta pelo acesso ao precioso líquido." (grifo nosso)

No Brasil, o Código de Águas, de 1937, foi um marco na legislação das águas no país. As legislações das águas doces reconhecem a água como bem de valor econômico, porém, devendo seu acesso em tempo de escassez, ser prioritário para consumo humano e dessedentação de animais. A Constituição Federal da República de 1988, não concebe a água como um direito fundamental. Ela é considerada no documento como um bem de valor econômico, de propriedade da União e dos Estados.

A Política Nacional de Recursos Hídricos (PNRH), de 1997, no título I, Cap. 1, dos Fundamentos, Art. 1, declara que “a água é um recurso natural limitado, dotado de valor econômico", sendo que em situações de escassez seu uso é prioritário para o consumo humano e dessedentação de animais. 
A Lei de Saneamento Básico de 2007, ao tratar da universalidade do acesso a água, à saúde pública, ao meio ambiente, e a oferta dos serviços de água com regularidade e qualidade, incorpora uma concepção de direitos humanos.

Outra legislação relevante para a segurança hídrica é a Política Nacional de Segurança Alimentar e Nutricional (PNSAN), de 2010, que trata da promoção do acesso universal a água. O artigo 3, inciso VI, da PNSAN, reconhece a relevância da água para o direito a alimentação, ao referir-se que o Estado tem como responsabilidade atuar na

“promoção do acesso universal a água de qualidade e em quantidade suficiente, com prioridade para as famílias em situação de insegurança hídrica, e para a produção de alimentos na agricultura familiar, como também para a pesca e a aquicultura."

Desta forma, visando a efetivação do acesso a água como elemento importante para segurança alimentar e nutricional das famílias, o governo federal implementou o Programa Água para Todos (criado pelo Decreto no 7.535, de 26), de julho de 2011, que possui como diretriz a utilização de tecnologias sociais para captação e armazenamento de água pluvial. Este programa integra o Plano Brasil sem Miséria, de junho de 2011, do Ministério do Desenvolvimento Social e Combate a Fome (MDS) ${ }^{1}$, que desenvolve várias frentes de ação visando a erradicação da pobreza extrema, incluindo também o Programa Cisternas, que beneficia famílias do semiárido brasileiro. Esses programas trazem benefícios, como a diminuição de deslocamentos em busca da água, à saúde e ao desenvolvimento social das famílias.

Em julho de 2010, o acesso à água e ao saneamento foi reconhecido como Direito Humano pela ONU, com voto favorável do Brasil. Mesmo que o direito a água não seja reconhecido pela Constituição Federal Brasileira, esta reconhece o direito à saúde, à alimentação e moradia, que para serem efetivados precisam do acesso à água, garantindo assim, a segurança hídrica, que segundo a Un-Water (2013), é

“[...] a capacidade da população de garantir o acesso sustentável à quantidade adequada e qualidade aceitável para os meios de subsistência, bem-estar humano e desenvolvimento socioeconômico, para assegurar a proteção contra a poluição e os desastres relacionados com a água, e para

\footnotetext{
${ }^{1}$ Com a ascensão de Michel Temer a presidência da república, em agosto de 2016, o MDS passou a se chamar Ministério do Desenvolvimento social e agrário.
} 
a preservação dos ecossistemas em um clima de paz e estabilidade política."

\section{Desenvolvimento econômico, impactos socioambientais e a insegurança hídrica.}

Mesmo com garantias positivadas internacionalmente e pelo Estado brasileiro, o direito a água é constantemente ameaçado e negado, pelas razões expostas acima, e especificamente neste trabalho, pelos impactos socioambientais, quando da construção e operacionalização de grandes obras e empreendimentos, colocando em questão a efetividade das politicas públicas na preservação do meio ambiente e consequentemente, preservação das condições de vida e subsistência da população.

No Brasil, a política ambiental tem como finalidade intervir nas desigualdades, buscando um equilíbrio entre desenvolvimento econômico e as demais dimensões social, cultural e ambiental e, por meio de condicionantes, buscar equilíbrio entre interesses distintos. Desta forma, a Politica Nacional de Meio Ambiente (PNMA), de 1981, exige o licenciamento ambiental para obra ou atividade potencialmente causadora de impacto e degradação ambiental. Para isso, com base na Resolução 001/86, do Conselho Nacional de Meio Ambiente (CONAMA), Art. 1丷.

"considera-se impacto ambiental qualquer alteração das propriedades físicas, químicas e biológicas do meio ambiente, causada por qualquer forma de matéria ou energia resultante das atividades humanas que, direta ou indiretamente, afetam:

I - a saúde, a segurança e o bem-estar da população;

II - as atividades sociais e econômicas;

III - a biota;

IV - as condições estéticas e sanitárias do meio ambiente;

$\mathrm{V}$ - a qualidade dos recursos ambientais. [...]"

Todavia, em contexto de competitividade econômica acirrada, as empresas capitalistas, além de buscarem mão-de-obra barata como forma de diminuição de custos e, lançando mão do trabalho infantil, do trabalho feminino, da flexibilidade dos vínculos trabalhistas (com intensificação da precarização), procuram territórios com disponibilidade de recursos naturais para extração e exploração, intensificando a degradação ambiental, com poluição hídrica, atmosférica, impactos danosos aos ecossistemas, além de alteração nos 
modos de vida e subsistência de comunidades humanas (HARVEY, 2009; ANTUNES, 2006; ALVES, 2005).

Destarte, considera-se como explicação para as violações, a imposição dos organismos multilaterais pela implementação de ajustes fiscais, aliada ao discurso ideológico da falência e ineficiência do Estado, e a internacionalização da economia, e, por conseguinte, alteração nos mecanismos de proteção social que considerando as especificidades de países em desenvolvimento, diante dos graves problemas econômicopolíticos, sociais e financeiros enfrentados, apresentam um quadro profundo de desigualdade e pobreza.

Nesse cenário, há uma ampliação do poder do mercado diante da fragilização do Estado na garantia, proteção e promoção de direitos, e a relevância das instituições que compõem a sociedade civil, para junto com o Estado e o Mercado intervirem na pobreza extrema e em suas consequências (não nas causas). Visa entre outros, a necessidade de garantir segurança para os negócios e para os ricos, de onde advêm violações de direitos civis e políticos, como exemplo, na guerra contra o terrorismo e contra as drogas.

Conforme Dornelles (2007, p. 207) com base no Relatório sobre Desenvolvimento Humano (2000-2002), considerando somente as últimas décadas do século XX, foram registrados 45 acidentes de repercussão social em indústrias localizadas em países em desenvolvimento.

“Dos, aproximadamente, 4,4 bilhões de pessoas que vivem em países em desenvolvimento, um número considerável de pessoas tem sua vida afetada por questões sócio-economicas-ambientais: cerca de 60\% necessitam de saneamento básico, $1 / 3$ não tem acesso à água potável (salubre), 1/4 não dispõe de habitação adequada; $20 \%$ das crianças não frequentam a escola até o final do quinto ano e mais de $8 \%$ das crianças morrem antes de completar os cinco anos de vida. A pobreza e a miséria têm consequências geracionais, comprometendo a vida de gerações de pessoas, que sem desejarem estarão contribuindo para uma nova categoria social, não mais de pobres, nem de extremamente pobres, como 'gentilmente' são chamados os miseráveis, estes serão os surnumérareis."

Ainda segundo a autora (2007, p. 209), “o que se constata é a pobreza mundial, o crescimento da desigualdade entre e dentro dos países, a exclusão das pessoas e países pobres, e a persistência de abusos dos direitos humanos." É a ampliação da iniquidade dos 
povos com aumento do número de refugiados, migrantes, questão ambientais, conflitos de toda ordem, terrorismo e instabilidade social.

Nesse contexto, entre os violadores dos direitos humanos estão empresas transnacionais, grandes conglomerados, organismos financeiros, fundos de pensão, associações de classe patronais e sindicatos, além do próprio Estado Nacional, em sua desresponsabilização, omissão e consequente desproteção de direitos.

Para Alves (2002; 2005) as violações são cometidas por agentes e órgãos estatais e não estatais. Aos primeiros cabe a função de proteger e assegurar liberdade, dignidade humana e bem-estar, na perspectiva da justiça social e dos valores democráticos, para isso garantindo por meio de políticas públicas a efetivação dos direitos. Entretanto, violações relacionadas à administração e gestão públicas são cometidas pelo Estado, como privação ou desigualdade do acesso a direitos, não acesso a informação, não transparência na construção de grandes obras, nas concessões estatais, nas obras privadas subsidiadas com recursos públicos.

De acordo com Timo (2013), partindo do suposto que desenvolvimento não se restringe a crescimento econômico, pelo contrário, desenvolvimento implica na associação intrínseca com a garantia de direitos, sendo indissociáveis pelos princípios humanos que objetivam alcançar, como liberdade e dignidade humana, no Brasil é caracterizado como predatório.

Prioriza-se grandes obras de infraestrutura, megaempreendimentos que seguem a lógica da aceleração do crescimento ${ }^{2}$, com exploração dos recursos naturais e humanos, e a custa de violação de direitos de povos tradicionais, como indígenas, quilombolas, pescadores artesanais e pequenos agricultores. Nas áreas urbanas, segue-se a mesma lógica, com transformação das cidades em "cidades-espetáculo", cidades-mercadoria. Para isso, efetivam-se os deslocamentos forçados, produzindo rompimento de vínculos familiares e comunitários além de outras consequências, em total desprezo à dignidade do ser social.

Neste quadro, dentre as violações mais graves e ocorridas de forma reiterada, estão alterações na vida e cultura de povos tradicionais, exploração dos recursos naturais, remoções forçadas sem compensação, danos ambientais, inserção de trabalhadores em condições degradantes, semelhantes à escravidão, trabalho infantil, exploração sexual de crianças e adolescentes (PIOVESAN, 2004).

\footnotetext{
${ }^{2}$ Visando o desenvolvimento econômico, em 2007 e 2011, foram lançados nos governos Lula e Dilma respectivamente, o PAC (Programa de Aceleração do Crescimento), para investimento em grandes obras de infraestrutura, entre elas os portos.
} 
As grandes obras e empreendimentos, que por meio de parcerias público-privadas se instalam em territórios tidos como "atrasados", do ponto de vista econômico e social, fazem parte de um projeto macro de internacionalização da economia, via políticas de desenvolvimento econômico, que tem o Banco Nacional de Desenvolvimento Econômico e Social (BNDES) ${ }^{3}$ como principal instituição de fomento, entretanto, não atenta para os interesses das populações na perspectiva dos direitos humanos.

A publicação do CONECTAS (2014, p. 5) observa que não há por parte da principal instituição estatal de fomento ao desenvolvimento, políticas e programas compatíveis com a proteção aos direitos humanos, centrados nas pessoas e na dignidade humana, comprometidos com normativas internacionais e nacionais de proteção os direitos humanos e de desenvolvimento de medidas para evitar que tomadores de empréstimos violem direitos, como por exemplo, as condições de financiamento para projetos que gerarão impactos nos territórios, especialmente de povos tradicionais.

"Os déficits de transparência e de abertura à participação social do BNDES contribuem, por sua vez, para que as ferramentas de prevenção, mitigação e monitoramento de impactos socioambientais e de direitos humanos empregadas pelo Banco nas diversas fases do ciclo do projeto tenham um desempenho aquém do desejável. Apesar da existência de uma Política Socioambiental que prevê instrumentos de avaliação de riscos socioambientais, são inúmeras as denúncias de violações de direitos humanos no âmbito de projetos financiados pelo BNDES." (grifo no original)

Para Sampaio (2012) e Maranhão (2012), o que está em curso no Brasil é um modelo de desenvolvimento, cunhado de neodesenvolvimentismo, que defende o alcance do bem estar social por meio de altas taxas de crescimento econômico, via internacionalização econômico-financeira do país e intervenção do Estado, no papel de promotor de grandes projetos público-privados. Para Sampaio (2012, p. 681-682) o neodesenvolvimentismo “[...] Ignora as contradições estruturais que regem o movimento da economia brasileira". Os adeptos dessa perspectiva de desenvolvimento não percebem que o Estado está refém dos interesses do grande capital, e do que essa articulação traz: a permanente "dependência externa e a segregação social". Conforme o autor (2012, p. 683).

\footnotetext{
${ }^{3}$ O Banco Nacional de Desenvolvimento Econômico e Social (BNDES), fundado em 1952, tem formulado e executado políticas e programas de desenvolvimento para o país.
} 
“O neodesenvolvimentismo só pode fantasiar sobre a possibilidade de um desenvolvimento capitalista nacional porque ignora os encadeamentos necessários entre concentração e centralização dos capitais, dominância absoluta do capital financeiro sobre o processo de acumulação, lógica de império que preside a ação das potências imperialistas (Estados Unidos à frente), total subordinação da ordem econômica mundial aos imperativos do capital financeiro, incontrolabilidade do capital, crise terminal do keynesianismo e tendência à reversão neocolonial nos países que fazem parte da periferia da economia mundial. No que se refere à peculiaridade da situação do Brasil no contexto mundial, a inversão da realidade assume a forma de uma desconsideração do impacto particularmente devastador da etapa superior do imperialismo sobre todas as dimensões da vida nacional."

Na Declaração sobre os Direitos ao Desenvolvimento (1986), o desenvolvimento refere-se a um processo social, politico, econômico e cultural que tem como objetivo assegurar bemestar para indivíduos e populações e a participação destes na justa distribuição dos benefícios alcançados, com ações de promoção e proteção dos direitos humanos. Em seu artigo $2^{\circ}$ diz: "a pessoa humana é o sujeito central do desenvolvimento [...] e beneficiária do direito ao desenvolvimento". Nesse sentido, os Estados devem adotar medidas de desenvolvimento com vistas a sua plena realização, reconhecendo a interdependência entre democracia, desenvolvimento e os direitos humanos. (PIOVESAN, 2004)

\section{O Complexo logístico, industrial e portuário do Açu - CLIPA, no norte do estado do Rio} de Janeiro.

O norte do estado do Rio de Janeiro é uma mesorregião, formada pelas microrregiões Campos dos Goytacazes e Macaé. Compõem a microrregião Campos dos Goytacazes, os municípios de Campos dos Goytacazes, São João da Barra, São Francisco do Itabapoana, São Fidélis e Cardoso Moreira. A microrregião Macaé é composta pelos municípios de Macaé, Quissamã, Carapebus, Conceição de Macabú (IBGE, 2010). De tradição agrícola, a região norte do estado do Rio de Janeiro, tem como principal produto a cana-de-açúcar, base de sua economia, com instalação de engenhos e posteriormente, usinas, na região. 
Em finais da década de 1980, a região conheceu a estagnação de sua principal atividade econômica e outro ciclo se iniciou, com a extração de petróleo e seus derivados na Bacia de Campos, e mais atualmente, nos anos 2000, grandes obras de infraestrutura como o CLIPA, com parte de sua estrutura em fase de operação desde 2014, no V Distrito do município de São João da Barra.

O município de São João da Barra possui uma população de 32.747, sendo que deste número, 25.693 habitantes residem na área urbana e 7.054, na área rural. (IBGE, 2010). Possui uma extensão territorial de 455.044 quilômetros quadrados. Tem como principais atividades econômicas a agricultura, o turismo e a pesca. As localidades como Água Preta, Amparo, Cajueiro, Campo da Praia, Degredo, Grussaí, Mato Escuro, Palacete, Pipeiras e Praia do Açu são as mais afetadas pela construção do CLIPA. Nessas localidades são desenvolvidas a agricultura de subsistência, agricultura familiar, com a cultura do abacaxi, quiabo, maxixe e aipim, além da pesca e pecuária, e possui uma população em torno de 12.210 habitantes, sendo esta a mais afetada pelas desapropriações de terras e consequente deslocamentos forçados, além de outros impactos socioambientais. (XAVIER; JUNIOR, p. 2013, p. 121)

Conforme Latini (2016), desde 1999, com o Decreto estadual n. 25.455, de junho, algumas áreas rurais localizadas no V Distrito de São João da Barra, passaram a ser de utilidade pública pelo governo do estado do Rio de Janeiro, para a implantação do Distrito Industrial de São João da Barra (DISJB) (Figura 1). O DISJB tem como órgão responsável a Companhia de Desenvolvimento Industrial do estado do Rio de Janeiro (CODIN), que, em entendimento com a extinta LLX, empresa que pertencia ao grupo EBX, do empresário Eike Batista ${ }^{4}$, firmou acordo para instalação do CLIPA.

Segundo o Estudo de Impacto Ambiental (EIA) e o respectivo Relatório de Impacto ambiental (RIMA) do DISJB (LLX/ECOLOGUS/AGRAR, 2011, p.4), o DISJB

“é uma grande área próxima da costa com 7.036 hectares, vizinha à Zona Industrial do Porto do Açu - ZIPA. O conjunto de empreendimentos em andamento na ZIPA mais os planejados para o DISJB formam o Complexo Logístico e Industrial do Porto do Açu - CLIPA."

As obras do CLIPA foram iniciadas em 2007, como parte do projeto Minas-Rio de Eike Batista, formado pela extração de minério de ferro nos municípios mineiros de Conceição do Mato Dentro e Alvorada de Minas, cadeia de beneficiamento, construção de um

\footnotetext{
${ }^{4}$ Empresário brasileiro do ramo de logística e extração mineral. Proprietário da holding EBX.
} 
mineroduto de Conceição do Mato Dentro ao Porto do Açu, e dele, a exportação do produto.

Em 2013, devido à crise nos negócios do grupo EBX, o CLIPA foi vendido, e seu controle acionário passou a ser da empresa Prumo Logística Global (Prumo), pertencente a EIG Global Energy Partners, holding americana. Desta feita, com a mudança acionária, o projeto do complexo, que foi concebido como parte do Sistema Minas-Rio foi alterado. Porém, o porto, principal empreendimento do complexo, foi mantido, assim como outros empreendimentos, pela atual controladora.

Conforme relatório sobre o empreendimento realizado por Mendonça et al (2011), com base no EIA/RIMA do DISJB (LLX/ECOLOGUS/AGRAR, 2011), foi previsto um conjunto de empreendimentos, como um terminal portuário, indústrias petroquímicas, pólo de metal-mecânico, siderurgias, termoelétricas e um mineroduto, contanto para essa construção, com capital público e privado, tanto nacional quanto estrangeiro.

O mesmo relatório previu que o porto, maior empreendimento do complexo, provocaria impactos, principalmente nos municípios de Campos dos Goytacazes e São João da Barra, por abrigarem as operações portuárias e industriais, e obras de infraestrutura, sendo as localidades do entorno do complexo as áreas diretamente afetadas.

Desde seu processo de licenciamento ambiental, o CLIPA tem sido alvo de constantes conflitos de proprietário rurais, pequenos agricultores, com a empresa controladora e a CODIN, e com judicialização desses conflitos no Ministério Público Federal, motivados pelas desapropriações e por outros impactos socioambientais. 


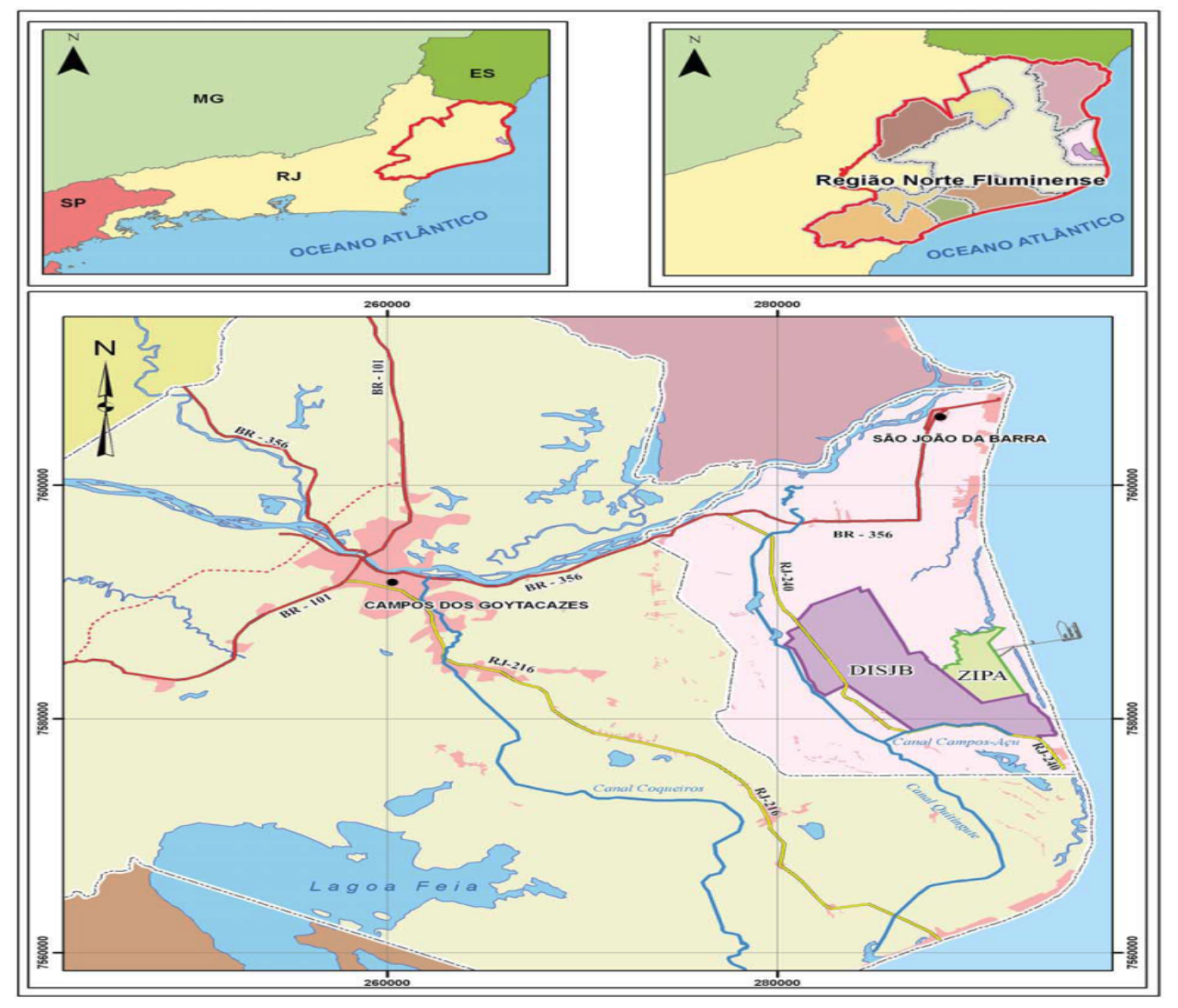

Figura 1 - Mapa de localização do DISJB e da ZIPA onde se localiza o CLIPA.

Fonte: RIMA - Relatório de Impacto Ambiental (LLX/ECOLOGUS/AGRAR, 2011, p. 2).

Em se tratando dos impactos relacionados à água, de acordo com o EIA/RIMA do DISJB e com Mendonça et al (2011), a operacionalização das atividades do complexo, em sua capacidade máxima, demandará aumento por abastecimento de água para as atividades industriais e portuárias, bem como para consumo humano. Somado à demanda por água está o tratamento de resíduos, tanto domésticos quanto industriais, e a vulnerabilidade em que os corpos hídricos estarão sujeitos, pela contaminação e poluição das suas águas. Mendonça et al (2011, p. 12) observam que

"os impactos do distrito industrial sobre os recursos hídricos da região abrangerão não só a contaminação desses corpos hídricos superficiais ou subterrâneos, mas também a alteração do fluxo subterrâneo, com possibilidade de salinização de águas costeiras, e a geração de efluentes industriais e domésticos lançados por meio de emissário submarino em áreas de pesca." 
O empreendimento, a fim de prevenir impactos em corpos hídricos na fase de construção do CLIPA, criou o Programa de Monitoramento dos Ecossistemas Aquáticos e Aquífero livre e o Plano Ambiental de Construção e Programa de Gerenciamento de Resíduos e Efluentes, visando acompanhar a qualidade da água dos corpos de água do entorno do empreendimento, tanto os superficiais quanto os subterrâneos e o gerenciamento de resíduos. (RIMA/DISJB - LLX/ECOLOGUS/AGRAR, 2011, p. 68)

Latini (2016, p. 94) verificou um total de 99 impactos (para os meios biótico, físico e socioeconômico) previstos para as áreas sob influência do CLIPA. No aspecto socioeconômico, os impactos negativos estão nos riscos sociais relacionados a aumento da demanda por serviços públicos, infraestrutura e impacto nas atividades agrícolas, além da "alteração da qualidade das águas."

Com base no RIMA do DISJB (LLX/ECOLOGUS/AGRAR, p. 10), os principais corpos hídricos do entorno do CLIPA são as Lagoas de Grussaí, de Iquipari, do Veiga, Salgada, além das lagoas do Taí e do Açu e uma rede de drenagem composta por vários canais, como Canal Quitingute, Canal São Bento e outros, localizados no DISJB.

O mesmo documento, referindo-se a qualidade da água nas lagoas e canais da área estudada, constata que as águas dos canais possuem condições de água doce, com salinidade menor que 0,5 e as lagoas, pela proximidade com o mar, oscilam entre doce e salobra, com valores de salinidade superior a 0,5 e inferior a 30,0. (ibid., 2011, p. 38)

Quando da construção do aterro hidráulico (Figura 2) e da construção do canal de navegação da UCN, foram realizadas obras na rede de drenagem e de dragagem da Lagoa do Veiga para abertura do canal, e o material escavado pela dragagem foi utilizado para a construção do aterro hidráulico. Além do material (97\% de areia) retirado na dragagem, o EIA previu que para complementação de material para o aterro seria necessário a dragagem marítima, porém, isso colocaria no aterro quantidade considerável de água do mar, sendo necessário fazer a drenagem dessa água.

O RIMA do DISJB (LLX/ECOLOGUS/AGRAR, 2011, p. 72), ao referir-se a construção do aterro hidráulico e propriamente à descarga de água salina no terreno para a construção do aterro, avaliou que o impacto seria de baixa magnitude:

“Para a constituição do aterro será necessário o aporte de grande volume de material, estimado em aproximadamente 44 milhões de metros cúbicos. [...]. Esta alternativa de aterro hidráulico implicaria no lançamento sobre o terreno, de areia com considerável quantidade de água do mar. Apesar dos dispositivos previstos no projeto para retorno hidráulico da água para o mar logo após o lançamento do aterro, poderá haver infiltração de água 
salina no lençol de água superficial, o que poderia provocar uma alteração temporária na salinidade, assim como na qualidade de água dos corpos hídricos. Estes impactos serão monitorados durante a obra conforme diretrizes proposta no Programa de Monitoramento dos Ecossistemas Aquáticos e Aquífero. Ressalta-se que o lençol de água e os corpos hídricos, como as lagoas de Iquipari, Grussaí e Açu, apresentam variação de salinidade para condições de água doce e salobra, sendo Impactos Ambientais este, por si só, um fator que minimiza o eventual impacto descrito."

Mesmo com a drenagem da água do mar lançada sobre o aterro hidráulico, ocorreu infiltração de água salina no lençol freático, como previsto pelo EIA e constatado por pesquisa realizada pela UENF (Universidade Estadual do Norte Fluminense), como relata Latini (2016, p. 102):

“No final do ano de 2012, pesquisadores do Laboratório de Ciências Ambientais da Uenf, realizaram coletas de águas em diversos pontos do $\mathrm{V}$ Distrito de São João da Barra a pedido dos agricultores que suspeitavam de alterações na qualidade das águas existentes em suas propriedades. Os resultados indicaram que as águas do Canal do Quitingute e de outros corpos hídricos apresentavam valores elevados de salinidade, o que foi relacionado à construção do aterro hidráulico do CLIPA. Agricultores também denunciaram perdas significativas de plantações relacionando tais perdas à elevada salinidade das águas de irrigação." (grifo nosso).

Além da UENF, pesquisadores do IFF (Instituto Federal Fluminense, 2013) também identificaram que os padrões de salinidade da água utilizada pela irrigação proveniente do Canal do Quitingute $^{5}$ (que segundo o EIA/RIMA do DISB, quando da ocasião do estudo de impacto, apresentava sistema típico de água doce), não estavam adequados.

Latini (2016, p. 108) também realizou pesquisa para identificar se o aterro hidráulico afetou as águas. A mesma relata:

\footnotetext{
${ }^{5}$ O canal do Quitingute faz parte de um sistema que começa no rio Paraíba do Sul e termina no rio do Viegas, próximo ao Farol de São Tomé, em Campos dos Goytacazes, integrando em seu trajeto as lagoas Taí e Salgada, importantes para a região. (RIMA LLX/ECOLOGUS/AGRAR, 2011, p. 64)
} 
"Das amostras de água florada ${ }^{6}, 4$ foram classificadas como "salgada" [...] os três primeiros valores são provenientes de amostras coletadas próximas ao aterro hidráulico enquanto que o último valor é proveniente de uma propriedade rural em Água Preta, que foi atingida de forma direta pela intrusão de água salgada oriunda do aterro hidráulico do CIPLA em 2012. O dono dessa propriedade já entrou com processo judicial contra a LLX e a OGX por danos morais e materiais oriundos de dano ambiental consequente da salinização das águas de sua propriedade." (grifo nosso)

Corrobora com Latini, Rangel (2013, p. 30), que ao tratar do sistema de drenagem do local onde está instalado o CLIPA, diz que "o aterro hidráulico [...], seria um dos fatores da salinização das águas e do solo.".

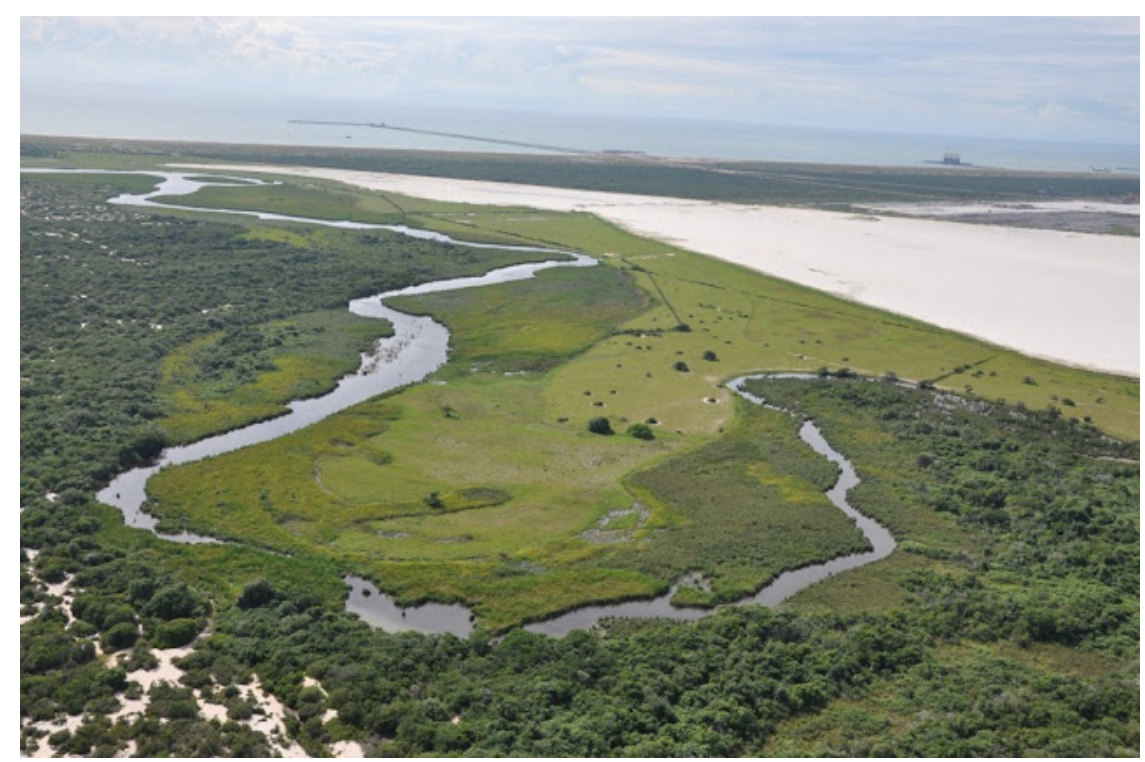

Figura 2 - Lagoa de Iquipari ${ }^{7}$, margeada pelo aterro hidráulico.

Fonte: Roberto Moraes, 2013.

\footnotetext{
${ }^{6}$ Conforme Latini (2016, p. 105), “a fim de identificar a salinidade das águas, as amostra foram originadas de três conjuntos: água para abastecimento público; água aflorada (reservatórios de diferentes tamanhos abertos pelos produtores); água de campo (poços rasos utilizados pelos produtores para irrigação). As medições ocorreram entre os meses de abril e agosto de 2015, totalizando 110 amostras."
}

7 A Lagoa de Iquipari situa-se em Pipeiras, $5^{\circ}$ distrito do município de São João da Barra/RJ, na Região Norte Fluminense do estado do Rio de Janeiro [...], sendo classificada como uma lagoa de restinga. [...]. (VILAÇA, 2015, p. 19 e 34) 
Para Rangel (2013, p. 31) “A proximidade do aterro com alguns corpos hídricos da região, como o Canal Quintigute e a Lagoa de Iquipari torna-se mais um fato preocupante diante dos já comprovados impactos da salinização.".

Sobre os impactos, uma moradora da região, pescadora, de 66 anos, retrata as condições em que vive:

“A água está salobra, muito salgada. O peixe Preto morre com água salgada e a Traíra também não resiste. Até os camarões e siris estão morrendo. Está escasso de se conseguir peixe aqui [...]. Antigamente, á água não era assim. E isso vai nos causar muito prejuízo. Como a gente vai sobreviver sem peixe na lagoa, já que vivemos disso?" (GREVI, 2013 on line)

Por conta da salinidade das águas do Canal do Quitingute, utilizado para irrigação por proprietários rurais, a empresa OSX (do grupo EBX) foi multada, obrigada a apoiar financeiramente a implantação do Parque Estadual do $\mathrm{Açu}^{8}$, e a dragar pontos assoreados do referido canal, a fim de dar celeridade à diluição dos sais. Porém, segundo Latini (2016), o Ministério Público Federal (MPF) não aceitou recurso da empresa de restringir a reparação ao Canal do Quitingute, mas, que a reparação considerasse toda a extensão do $\mathrm{V}$ Distrito de São João da Barra.

\section{Considerações finais}

Os impactos socioambientais tem relação, como apontado neste trabalho, com o modelo de desenvolvimento econômico, principalmente de países que figuram na periferização do sistema econômico mundial, onde as grandes obras de infraestrutura fazem parte de um projeto de mundialização da economia, que, a fim de atender interesses econômicos nacionais e internacionais, cria as condições trabalhistas, ambientais, fiscais, para favorecer a instalação de grandes empreendimentos, que produzem nos territórios toda a sorte de violação de direitos, secundarizando as necessidades sociais das populações em nome do "progresso".

\footnotetext{
${ }^{8}$ Em relação ao Parque Estadual do Açu, este foi criado pelo Decreto estadual 43.522/2012. É uma unidade de conservação (UC), que juntamente com a AP de Grussaí, foram priorizadas no RIMA do DISJB (LLX/ECOLOGUS/AGRAR, 2011, p. 98) para receberem recursos financeiros, como medida de compensação.
} 
Com base no Conselho Nacional de Meio Ambiente (CONAMA), Resolução n. 001/86, o EIA deve desenvolver um diagnóstico ambiental da área de influência considerando os impactos aos meios físico, biótico e socioeconômico. O meio socioeconômico diz respeito ao uso e ocupação do solo, uso das águas, a dependência da sociedade local com os recursos ambientais, e a utilização futura desses recursos. O MPF, analisando alguns EIAs, ratifica que a avaliação de impacto ambiental (AIA) deve prever “os efeitos relacionados à degradação e a poluição provocados pelos empreendimentos de desenvolvimento econômico [...]" (MINISTÉRIO PÚBLICO DA UNIÃO, 2004, p. 7).

Entretanto, os programas de prevenção de poluição, contaminação e de alteração da qualidade da água de corpos superficiais e subterrâneos elaborados pelo empreendimento, não se mostraram eficazes na prevenção da salinização das águas, principalmente do canal do Quitingute, utilizado pelos agricultores da região para irrigação e dessedentação de animais, pelo contrário, o impacto foi subestimando no EIA, não apresentando medida efetiva para reverter o dano.

O EIA/RIMA do DISJB apresentou o Programa Monitoramento dos Ecossistemas Aquáticos e Aquífero livre, que segundo o documento, "abrange a investigação da eficiência das medidas mitigadoras sobre ecossistemas aquáticos e aquífero [...]. (LLX/ECOLOGUS/AGRAR, 2011, p. 99), no entanto, não apresentou nenhuma ação que minimizasse o eventual impacto.

Tal fato demonstra que a insegurança hídrica, como um dos impactos socioambientais relacionados a grandes empreendimentos, deve ser identificada e nomeada como tal no EIA/RIMA, a fim de que os órgãos de licenciamento ambiental exijam a implementação de condicionantes que compensem ou mitiguem os impactos nas águas, visando garantir o acesso à água pelas comunidades afetadas, como preconizam o direito humano a água e ao desenvolvimento, e como refere-se a PNSAN, sobre a garantia da água para a produção de alimentos e para a pesca.

Ora, o acesso a água deve ser garantido para "todas as manifestações da vida". Significa dizer que a centralidade da água vai além da necessidade vital de água potável, diz respeito a garantia dos modos de vida e subsistência das comunidades locais.

\section{Referências bibliográficas}

AGENDA 21. Conferência das Nações Unidas sobre o Meio Ambiente e Desenvolvimento (1992). Brasília: Gráfica do Senado Federal, 1996. 
ALVES, José A. Lindgren. Os Direitos Humanos na pós-modernidade. São Paulo: Perspectiva, 2005.

O Contrário dos Direitos Humanos (explicitando Zizek). Lua Nova, n. 55-56, 2002. Disponível em $<$ http://www.scielo.br/pdf/ln/n55-56/a05n5556.pdf >. Acesso em: 25 de abril de 2016.

ANTUNES, Ricardo. Adeus ao Trabalho? Ensaios sobre as metamorfoses e a centralidade no mundo do trabalho. São Paulo: Cortez, 2006.

BARBAN, Vilma. Fórum mundial da água: questões fundamentais e muitas controvérsias. Fórum Mundial da Água - questões fundamentais e muitas controvérsias. REDD, Revista Espaço de Diálogo e Desconexão. Araraquara, S/P, v.1, n.2, jan./ jul. 2009. Disponível em $<$ http://www.polis.org.br/uploads/504/504.pdf. $>$ Acesso em 16 de novembro de 2016.

BRASIL (1988). Constituição da República Federativa do Brasil. Brasília. Distrito Federal. Senado Federal, Centro Gráfico, 1988.

BRASIL. Lei Federal no. 9.433/1997. Institui a Política Nacional de Recursos Hídricos, cria o Sistema Nacional de Gerenciamento de Recursos Hídricos, regulamenta o inc. XIX do art. 21 da Constituição Federal, e altera o art. $1^{0}$ da Lei 8.001, de 13.03.1990, que modificou a Lei no. 7.990, de 28.12.1989. Disponível em: <http://www.planalto.gov.br>. Acesso em: 11 de outubro de 2015.

BRASIL. Lei 11.455/2007. Lei do Saneamento Básico. Estabelece diretrizes nacionais para o saneamento básico.

BRASIL. Decreto 7.272/2010. Institui a Política Nacional de Segurança Alimentar e Nutricional - PNSAN, estabelece os parâmetros para a elaboração do Plano Nacional de Segurança Alimentar e Nutricional, e dá outras providências. Disponível em $<$ http://www.planalto.gov.br/ccivil_03/_ato2007-2010/2010/decreto/d7272.htm>. Acesso em 21 de outubro de 2015.

CONECTAS Direitos Humanos. Desenvolvimento para as pessoas? O financiamento do BNDES e os direitos humanos. São Paulo, III Série, 2014.

CRUZ, J. L. V. Economia e desenvolvimento no norte fluminense: da cana de açúcar aos royalties do petróleo. Campos dos Goytacazes, WTC Editora, 2004.

CUNHA, Tássio B.; OLIVEIRA, Diego B. S. de. ; LINHARES, Franklin M.; SANTOS, José Y. G. dos.; VIANNA, Pedro C. G. Uma sinopse na política mundial da água. Anais do XVI 
Encontro Nacional dos Geógrafos (ENG) - "Crise, práxis e autonomia: espaços de resistência e de esperanças. Espaços de Diálogos e Práticas". Associação dos Geógrafos brasileiros: Porto Alegre, RS, 2010.

DIAS, Alexandre P; SOUZA, Alexandre A. de; MAIA, Aline B.; BERZINS, Félix A. J. Complexo Petroquímico do Rio de Janeiro (Comperj): Impactos socioambientais, violação de direitos e conflitos na Baía de Guanabara. Revista Ética e Filosofia Política, vol. 1, n. 16, junho, 2013.

Disponível em $<$ http://www.ufjf.br/eticaefilosofia/files/2009/08/16_1_pessoa.pdf $>$. Acesso em: 18 de fevereiro de 2016.

DORNELLES, Denise F. Direitos Humanos e Pobreza na sociedade contemporânea: não há equação possível. Rev. Serviço Social e Realidade. Franca. n. 16, 2º sem. 2007.

FERREIRA, Luciane. Do acesso à água e do seu reconhecimento como direito humano. Revista de Direito Público. Londrina, v. 6, n. 1, p. 55-69, Jan/Abr. 2011. Disponível em $<$ http://www.uel.br/revistas/uel/index.php/direitopub/article/view/8141/8445 $>$. Acesso em: 20 de outubro de 2015.

FLORES, Karen M. O Reconhecimento da água como direito fundamental e suas implicações. RFD- Revista da Faculdade de Direito da UERJ, v.1, n. 19, jun./dez 2011.

Disponível em: <http://www.e-publicacoes.uerj.br/index.php/rfduerj/article/view/1724>. Acesso em: 19 de outubro de 2015.

GORRITTI, Eliana. Vinte cidades tem o abastecimento de água extremamente crítico no ES. Em 12/08/16. Disponível em <http://g1.globo.com/espirito-santo/noticia/2016/08/vintecidades-tem-o-abastecimento-de-agua-extremamente-critico-no-es.html >. Acesso em: $12 \mathrm{de}$ novembro de 2016.

GOMES, Gustavo F. O Direito Fundamental à água e a Constituição de 1988. Trabalho publicado nos Anais do XIX ENCONTRO NACIONAL DO CONPEDI realizado em Fortaleza - CE nos dias 09, 10, 11 e 12 de Junho de 2010. Disponível em $<$ http://www.conpedi.org.br/manaus/arquivos/anais/fortaleza/4229.pdf $>$. Acesso em: $11 \mathrm{de}$ abril de 2015.

GREVI, Carlos. Pesquisa aponta altos níveis de salinização na Lagoa de Iquipari. Em 31 de janeiro de 2013. URURAU, on line. Disponível em: <http://ururau.com.br/cidades27135> Acesso em 16 de novembro de 2016.

HARVEY, David. Condição pós-moderna: uma pesquisa sobre as origens da mudança cultural. 18 ed. São Paulo: Ed. Loyola, 2009. 
IBAMA. Instituto Brasileiro do Meio Ambiente e dos Recursos Naturais Renováveis. Diretoria de Proteção Ambiental - DIPRO. Coordenação Geral de Emergências Ambientais - CGEMA. Laudo Técnico preliminar. Impactos ambientais decorrentes do desastre envolvendo o rompimento da barragem de Fundão, em Mariana, Minas Gerais, 2015. Disponível em: <http://www.ibama.gov.br/phocadownload/noticias_ambientais/laudo_tecnico_preliminar .pdf $>$ Acesso em: 13 de novembro de 2016.

IBGE-2010. Instituto Brasileiro de Geografia e Estatística. Censo Demográfico Brasileiro 2010.

INSTITUTO FEDERAL FLUMINENSE (IFF). Análise situacional dos produtores rurais ao longo do canal Quintigute (Microbacia do Rio Doce, São João da Barra, RJ) como subsídio a análise do eventual impacto na agricultura decorrente de alterações de salinidade pontual e transitória do referido canal. Fundação de apoio a Educação, Pesquisa e Desenvolvimento Científico e Tecnologia Fluminense - PRÒ-IFF, Campos dos Goytacazes, 2013.

LATINI, Juliana R. A Avaliação de Impacto Ambiental (AIA) enquanto instrumento participativo e preventivo no contexto do neodesenvolvimentismo: o caso do Complexo Logístico e Industrial do Porto do Açu (CLIPA). Dissertação (Mestrado em Ecologia e Recursos Naturais) Universidade Estadual do Norte Fluminense Darcy Ribeiro, 2016.

MACHADO. Paulo A. Recursos Hídricos: Direito Brasileiro e Internacional. São Paulo: Malheiros, 2002.

MARANHÃO, Cézar H. Desenvolvimento social como mercado: Amartya Sen e a renovação das promessas liberais. In: MOTA, Ana E. (org). Desenvolvimento e construção de hegemonia: crescimento econômico e reprodução da desigualdade. São Paulo: Cortez, 2012.

MENDONÇA, Débora; BARCELOS, Eduardo; MAROLA, Luis; CHUVA, Luiza; ALENTEJANO, Paulo; COSTA, Saulo. Relatório dos Impactos Socioambientais do Complexo Industrial-Portuário do Açu. Rio de Janeiro: Associação dos Geógrafos Brasileiros, $\quad$ set. 2011. Disponível: em <http://www.agb.org.br/documentos/Relatorio_dos_Impactos\%20socioambientais_do_Co mplexo_Portuario_do_Acu_AGB_14092011.pdf>. Acesso em: 19 de outubro de 2015.

MERCURI, Carlos. O Colapso de água em São Paulo. Revista Fórum Semanal. Em 16 de maio de 2014. Disponível em: <http://www.revistaforum.com.br/digital/147/o-colapso-daagua-em-sao-paulo/> Acesso em: 12 de novembro de 2016. 
MINISTÉRIO PÚBLICO DA UNIÃO. Deficiências em estudos de impacto ambiental. Síntese de uma experiência. Brasília: Ministério Público Federal, $4^{\text {a }}$ Câmara de Coordenação e Revisão: Escola Superior do Ministério Público da União, 2004. Disponível em <http://inspirebr.com.br/uploads/midiateca/3a81081c04be66765838effa84f22f0a.pdf> Acesso em: 14 de novembro de 2016.

MORAES, Roberto (blog) Lagoas de Grussaí e Iquipari em SJB. Em 28 de abril de 2013. Disponível em: <http://www.robertomoraes.com.br/2013/04/lagoas-de-grussai-e-iquipariem-sjb.html> Acesso em: 13 de novembro de 2016.

ONU. Organização das Nações Unidas. Declaração Universal dos Direitos Humanos. Disponível em: $<$ http://www.presidencia.gov.br/estrutura_presidencia/sedh/ $>$. Acesso em: 15 de outubro de 2015.

PIOVESAN, Flávia. Direitos sociais, econômicos e culturais e direitos civis e políticos. SUR. Revista Internacional de Direitos Humanos. Ano 1, n. 1, 1semestre 2004.

RANGEL, Larissa C. O Complexo Logístico Industrial Portuário do Açu e seus impactos no sistema de drenagem e na estruturação urbana da região norte-fluminense. Dissertação (Pós-Graduação em Engenharia Ambiental) - IFF. Campos dos Goytacazes, 2013.

RIBEIRO, W. C. Geografia Política da Água. São Paulo - SP, Ed. Annablume. 2008 RIMA. Relatório de Impacto Ambiental - Infraestruturas do Distrito Industrial de São João da Barra. LLX/ECOLOGUS/AGRAR, maio, 2011. Disponível em: $<$ http://www.inea.antigo.ri.gov.br/fma/download_rima.asp $>$. Acesso: em 18 de outubro de 2015.

SAMPAIO JR, Plínio de Arruda. Desenvolvimentismo e neodesenvolvimentismo: tragédia e farsa. Serv. Soc. Soc., São Paulo, n. 112, p. 672-688, out./dez. 2012.

TIMO, Petalla B. Desenvolvimento à custa de violações: impacto de megaprojetos nos Direitos Humanos no Brasil. SUR. Revista Internacional de Direitos Humanos / Sur - Rede Universitária de Direitos Humanos. v.10, n.18, jan.2013.

UN-WATER - The United Nations Inter-Agency mechanism on all freshwater related issues, including sanitation. Water security, 2013. Disponível em: $<$ http://www.unwater.org/topics/water-security/en/>. Acesso em: 17 de novembro de 2016.

VARGAS, Éverton V. Água e relações internacionais. Revista brasileira de política internacional. Brasília, vol. 43, n. 1, jan./jun. 2000. Disponível em: $<$ http://www.scielo.br/pdf/rbpi/v43n1/v43n1a10.pdf $>$ Acesso em: 04 de fevereiro de 2016. 
VILAÇA, Dayana R. C. O Complexo logístico Industrial Portuário do Açu (CLIPA) e seus reflexos na dinâmica ecossistêmica da Lagoa de Iquipari, São João da Barra/RJ. Dissertação (Pós-Graduação em Engenharia Ambiental) - IFF. Campos dos Goytacazes, 2015.

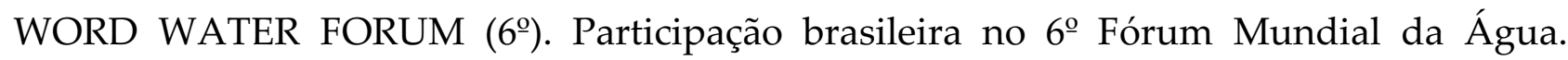
Marselle França, 2012. Disponível em:

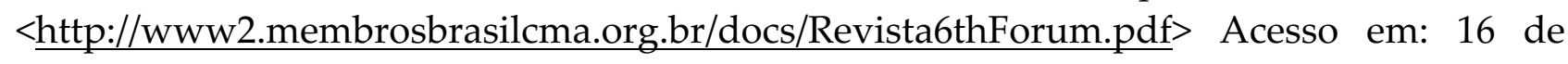
novembro de 2016.

XAVIER, Luís G. de Souza; QUINTO JUNIOR, Luiz de P. Os núcleos urbanos no entorno imediato do Complexo Industrial do Porto do Açu: alterações na paisagem. Boletim do Observatório Ambiental Alberto Ribeiro Lamego, Campos dos Goytacazes/RJ, v. 7 n. 2, p. 119-145, jul. / dez. 2013. Disponível em: $<\underline{\text { http://www.essentiaeditora.iff.edu.br/index.php/boletim/article/viewFile/2177- }}$ 4560.20130018/3005>. Acesso em: 19 de outubro de 2015.

ZHOURI, Andréa, OLIVEIRA, Raquel. Desenvolvimento, Conflitos Sociais e Violência no Brasil Rural: o caso das usinas hidrelétricas. Ambiente \& Sociedade, Campinas, v X, $\mathrm{n}^{\circ}$ 2, jul/dez. 2007. 